\title{
World Englishes and English as a Lingua Franca
}

\section{Approaches in Teaching Saudi EFL Learners}

\author{
Amal Alasmari \\ Dep. of English Language and Literature, Prince Sattam bin Abdulaziz University \\ Alkharj, Kingdom of Saudi Arabia \\ E-mail: amalalasmari.uni@gmail.com
}

\begin{abstract}
Received: September 20, 2018 Accepted: October 14, 2018 Published: October 16, 2018
doi:10.5296/ijele.v6i2.13785 URL: https://doi.org/10.5296/ijele.v6i2.13785
\end{abstract}

\begin{abstract}
This paper aims to explore two approaches to English language: the world Englishes approach and English as a lingua franca approach, focusing on the advantages and limitations of each approach. A brief introduction on the global spread of English language is provided; as well as a thorough examination of the current status of English language in kingdom of Saudi Arabia. The paper also explores the possible future adoption of either World Englishes or English as a Lingua Franca approach in teaching English language to Saudi EFL learners. The examination of the nature of English used by Saudi EFL learners reveals a number of issues. While it is clear that a localized variety is emerging in KSA which is acknowledged by some Saudi researchers, resistance to adopting a Saudi variety in teaching strongly exists among the majority of researchers and decision makers in Saudi Education. The reason behind this reluctance to acknowledge a Saudi variety of English might be the idea that this localized variety of English in KSA is not viewed as equal to varieties of outer circle countries where English language plays far more significant roles than in expanding circle countries. In addition, decisions on adopting one of the two approaches in teaching English language in KSA are not easy; more data must be obtained before making any major pedagogical decisions.
\end{abstract}

Keywords: English language, World Englishes, English as a Lingua Franca, EFL Saudi learners, Saudi English 


\section{The Spread of English Language}

Over the last two centuries, English language has spread all around the world and the users of English as a medium of communication are increasing rapidly. English is the most widely used language that the world has ever known (Kachru \& Nelson, 1996). According to Kachru \& Nelson (1996), the global spread of English happened through two means; the first was through the migration of large numbers of English speakers from England to other parts of the world such as, Australia, New Zealand, and North America. Although the English spoken in the new countries changed over time and became slightly different from the one that was spoken in the old country, this was not seen as an important issue due to the fact that all languages evolve continuously. The other mean of the global spread of English is the colonialism of Asia and Africa in which English was enforced on those societies. English remained significantly important in the colonized countries even after the end of colonialism simply because English became highly beneficial for the local populations (Kachru \& Nelson, 1996). The English varieties that existed in postcolonial societies somehow absorbed the local cultures.

There are nowadays more non-native speakers of English than there are native speakers. As Crystal (2006) points out that the estimated number of people who use English as their second language is 430 million while the number of people who use English as their first language is 330 million, excluding the number of learners which might approximately be one billion learners of English (cited in Deterding and Kirkpatrick , 2006). Moreover, Kachru states that a survey conducted by the India Today magazine found that 333 million people in India use English every day in their life which means that out of three people in India one uses English daily (cited in Foley, 2007). The people who use English as their second language do not isolate their cultures from the language but bring their cultures to the scene and adjust the language, or in other words localize English to suit their own cultures and societies. Foley (2007) points out that languages change according to the way people use it and in the case of English, which is used globally, it is shaped by its non-native speakers as by its native speakers. English has gained considerable influence not only among post-colonial societies but also among most other international societies.

\section{World Englishes Approach}

The populations in post-colonial communities were able to indigenize the English language that was introduced to them to suit their interests and cultural backgrounds. According to Bhatt (2005), English represented an additional resource for speakers in multilingual contexts in which they were able to use this resource in linguistic, sociolinguistic, and literary creativity. Foley (2007), also, states that the English language that was introduced to the new societies did not remain the same but changed according to the context and the use. In addition, Foley points out that new versions or varieties of English have emerged. Each one of these new varieties of English, which resulted from the localization of English language, is connected with a specific unique culture (Bhatt, 2005). 


\section{$\triangle$ Macrothink}

The varieties of English that exist especially in Kachru's outer circle (in which English has an institutionalized function and has significant roles in education, politics ..etc, e.g. India, Nigeria) should be seen as legitimate versions of English as British and American Englishes or any other varieties of English in the inner circle (e.g. Australian, New Zealand). This approach to the varieties of English promotes equality among the different varieties and the speakers of those varieties. For example, monolingual British English speakers and bilingual Indian English speakers are all considered native speakers of English. This approach to English is referred to as world Englishes approach. The world Englishes approach contradicts the common view of the superiority of the inner circle varieties and speakers over the outer circle ones. The speakers of English varieties from the outer circle have localized English and used it as their mother tongue. Consequently, they should be treated as non- native speakers but rather native speakers of English (Bhatt, 2005).

There are many issues related to the new varieties of English that exist in the outer circle and what we could describe as the old varieties of English e.g. American and British Englishes. The view of the varieties of English that exists in the inner circle specially the American and British Englishes as the standardized norms does not take into consideration other varieties that exist in the outer circle such as Indian English. To describe someone's English as being Indian English or Singaporean English or any other variety that is different from the inner circle varieties does not indicate that this particular variety is not as good as the inner circle ones. However, this view of the outer circle varieties has been challenged by other views such as the interlanguage theory that was adopted by Selinker (1992) and which considers the British and American varieties as the standardized Englishes and any differences between these varieties and the outer circle varieties are regarded as errors caused by L1 interference ( cited in Jenkins, 2006). According to Kachru and Nelson (1996), the description of English as being a second language for someone creates attitudinal problems because it implies that second is not as valuable as first and that the second is less worthy. Such view of the varieties of English in the outer circle cause people who speak one of these varieties to try to adopt either American or the British English regardless to whether this particular variety suits their cultural contexts or not ( Kachru and Nelson ,1996).

Other views, on the other hand, consider the varieties of English from another perspective. Stevens (1983, cited in Kachru and Nelson ,1996), for instance, points out that any English speaker uses a specific dialect and that standardized English is only one dialect among many others. Moreover, even though the two norms of English the American and British have differences either in spoken or written language, the speakers of both varieties understand each other without any serious problems. According to Kachru and Nelson (1996), 'Standard British and American users, on the whole, are expected to be rather tolerant of each others' English but are likely to be intolerant of the usage South Asians, Southeast Asians, West Africans, or East Africans'. However, if a comparison is made between the standardized and new varieties, similarities will be noticed among them rather than differences. In regard to the view that all varieties of English has the same position, there are speakers of the outer circle who do not try to adopt any of the inner circle varieties because they find that these varieties irrelevant to their sociocultural contexts (Jenkins, 2006). 
The view of the monolingual speakers of English as being more skillful teachers than multilingual speakers of English is not quite true. Most theories on language learning present the native speaker as the model for second language learners to imitate or a goal for them to achieve (Rajagopalan, 2004). Moreover, many learners of English in Asia believe that native speakers are better English teachers than non-native speakers (Lin et al, 2002). Such view, that favors monolingual English teachers, ignores the fact that in reality English is taught around the world mostly by non-native speakers to non-native speakers, and none of them have any contact with native speakers (Kachru and Nelson ,1996). Jenkins (2006), also, points out that some countries that belong to the outer and expanding circles (e.g. Hong Kong, Japan) might bring American or British teachers but they might lack training and their teaching skills are considered poor compared to non-native speakers who have better teaching skills gained in lengthy university degrees.

The world Englishes approach has specific characteristics and advantages that make it unique from other approaches to English such as global English approach. The world Englishes approach promotes diversity and emphasizes on the legitimation of the new varieties of English. According to Bhatt (2005), the local communities have adopted different strategies of resistance and negotiation to face the linguistic imperialism. Also, he states that Indian English speakers and writers were able to create their own English which combines both the richness of the local cultures and the homogenized global norms and which consequently provided both local and international identities for those speakers. Even though the middle classes in India have access to Educational resources for standardized English, they were appropriating the English language, like all the lower classes, in order to manage the conflict between the global and national life (Bhatt, 2005). The speakers of the outer circle varieties have valuable resources that monolingual speakers of the inner circle varieties do not have, and such resources are obtained from a comparative orientation that multilingual speakers possess and which enables them to compete with the speakers of standardized English for profit sharing in local and international linguistic markets (Bhatt, 2005). The world Englishes approach considers the good multilingual speaker as the target norm rather than the monolingual speaker and this idea is clearly seen in Indian Englishes. The local communities in India are moving away from the idea of the native speaker being the target norm to a target norm that is more appropriate to their local context (Bhatt, 2005).

\section{English as a Lingua Franca Approach}

the spread of English has been very clear in the countries of the outer circle, and this spread resulted in the emergence of different varieties of English each associated with its own local and cultural context. However, According to Jenkins (2009), in recent years the most wide spread of English in regard to numbers of speakers occurred in the countries of the expanding circle. In most expanding circle countries, English is traditionally considered as a foreign language that is learnt to communicate with inner circle speakers and which depends on inner circle norms. However, the purpose of learning English in the expanding circle countries has changed; learners in those countries learn English to communicate with speakers of other first 
languages rather than with English native speakers. Moreover, there are considerable evidence that speakers in expanding circle countries find that English based on the inner circle norms is no longer relevant to their international communication needs (Jenkins, 2009). Therefore, those learners use a variety of English or a lingua franca that is different from the inner circle varieties to communicate with speakers from different linguistic backgrounds.

According to Seidlhofer (2005), "the term English as a lingua franca (ELF) has emerged as a way of referring to communication in English between speakers with different first languages". Most ELF communications occur between nonnative speakers of English, particularly speakers of expanding circle countries who do not share neither a mother tongue nor a common national culture and who chose English as the foreign language for communication. The English as a lingua franca approach is different from the English as a foreign language approach (EFL) which is the traditional approach to English language learning in Expanding circle countries. The ELF is a part of the world Englishes paradigm and it celebrates differences from the inner circle norms, while EFL is a part of modern foreign languages which considers differences from the inner circle standard as errors. Code-switching in ELF approach is seen positively as an additional resource for speakers to show their multilingual identities. However, EFL approach views code-switching negatively as a way to solve the speaker's problem of lack of knowledge in English (Jenkins, 2009).

Learners of English from the expanding circle will benefit from the awareness of the emerging features of ELF approach. One of the important features that ELF speakers have is their ability to make accommodative adjustments in their communications with people from different cultural and linguistic backgrounds. In ELF model, accommodation strategy is used to promote the speaker's own identity and solidarity. Jenkins (2002) points out that ELF speakers adjust their language to be more similar to their interlocutors in order to be liked and to be understood. Moreover, code-switching is another feature of ELF speech in which speakers switch to their own first language to express solidarity and their multilingual identities. However, this strategy might lead to some confusion in conversations unless the participants involved in the conversation have some experience on the speaker's L1or the speaker provides explanations for the L1 words used in the speech.

The adoption of lingua franca model in learning will be beneficial for those who belong to the expanding circle countries and who intended to use English as a communication language with speakers of different L1 and different cultural backgrounds. However, if the purpose of learning English is to be for example an English teacher or to have any communication with native speakers, I believe the lingua franca model might not be very effective for such purposes. Nevertheless, The lingua franca model provides some liberation for both teachers and learners (Kirkpatrick, 2006). The native speaker model is no longer the target model for both teachers and learners who might be unable to follow such model and which might also be culturally irrelevant. In addition, the learners will be freed from the feeling that their English is not as good as the standard English and as a result the focus in the class will be on communication rather than on the acquisition of the standardized norms. Moreover, Kirkpatrick (2006) points out that lingua franca does not create the feeling among the learners that it is owned by someone else but it is owned by all speakers who are able to use it to 
express their own cultures and identities. Kirkpatrick, also, states that in learning English as a lingua franca more cultural content will be provided for the learners who will be able to learn more about the cultures of the people with whom they will probably use their English. Learning about other cultures is very essential for ELF learners because this will enable them to acquire and develop their accommodation skills. However, ELF classes, that teach learners about other cultures to develop their accommodation skills, usually have all learners with the same L1 and in the learners' own countries and this as Jenkins (2002) states presents a basic problem for the development of ELF learners' accommodation skills. Even though the learner will be provided with useful knowledge on other cultures, they will not have a real practice with speakers of different L1.

The ELF is a phenomena that resulted from the communications among non-native speakers of English. However, this approach is challenged by traditional EFL approach supporters who show negative attitudes towards the ELF approach. Yet, as Jenkins (2009) points out that 'in the near future, those who occupy the top of the English language hierarchy will no longer be native speakers of English, but bilingual speakers of English who have the skills to function comfortably in multilingual communication'. The reason that native speakers tend to be passive in such multilingual communication is that they are more constrained by the rules of English than non-native speakers who are more liberated in their use of English.

\section{An Evaluation of the Two Approaches}

The world Englishes approach and English as a lingua franca approach seem different in that the world Englishes model promotes diversity and the different varieties of English but the lingua franca model seems to focus on one model of English. According to Jenkins (2006), some world Englishes scholars consider ELF approach and English as an International Language approach as the same and therefore assume that ELF approach promotes a monocentric view of English based on the inner circle varieties. However, ELF researchers claim that there is no single ELF variety and it will never exist. Therefore, any of the local varieties would be acceptable in ELF approach. This view of ELF approach makes it difficult to differentiate between the two approaches. Jenkins (2006), emphasizes that both approaches agree on the need for a pluricentric rather than monocentric view of the use of English. The pluralisation approach enables learners and speakers of English to express their own sociolinguistic reality. However, the world Englishes model reflects the cultural norms of certain varieties while the ELF model reflects the cultural norms of anyone who use it (Kirkpatrick, 2006). Accommodation skills are also seen essential among speakers of both world Englishes and ELF. However, the problem that faces both approaches is to find a way to incorporate them into testing and that seem almost impossible with the ongoing negotiation of English language. Even though the ELF approach in particular seems highly controversial, it has at least addressed the issue of the expanding circle which has not been adequately dealt with in the world Englishes approach. Seidlhofer (2000) argues that ELF have the right to be described and identified the same right the World Englishes had; ELF has the right to be seen and dealt with as different from English as an international or global language. 


\section{English Language in KSA}

It is unquestionable that English has gained a remarkable status globally and KSA is not an exception. 'Today, along with China, Greece, and Brazil, KSA is credited to have the continuously expanding numbers of English learners in the World' (Crystal, 2003 cited in Alasmari \& Khan, 2014). As Kubota (2001) and Alasmari \& Khan (2014) note that Saudi Arabia belongs to the expanding circle countries in which English language does not hold an official status but taught widely as a foreign language. According to Mahboob \& Elyas (2014), the important current status which English language holds in KSA is partly because of its perceived economic value. As a result of the rapid developments at social and economic levels in KSA, and to cope with such developments English language was introduced in formal education (Alasmari \& Khan, 2014). English in KSA is gaining more significant status which is clearly reflected in the use of English as the medium of instruction for many courses in BA programs. Also, English language proficiency has become a prerequisite for admission in medicine and dentistry programs as well as higher degrees (Alasmari \& Khan, 2014).

\subsection{Saudi English}

Teaching English in Saudi Arabia is based on standardized British or American Englishes. Other varieties of English are not recognized or encouraged in formal educational contexts. Mahboob \& Elyas (2014) point out that the teaching of English language in KSA -as one of the expanding circle countries- is based on English norms (i.e. American and British Englishes). So, any instances in the English used by Saudi learners that differ from the inner circle varieties are viewed as mistakes rather than local adjustments. Mahboob \& Elyas (2014) also state that viewing differences between inner circle and expanding circle varieties as mistakes, is a way of resistance to the acknowledgement of arising local varieties of English in the expanding circle countries. However, Jenkins (2006) argues that speakers of the outer and expanding circles have the right to develop their own variety rather than following an irrelevant standardized norm. Based on Jenkins argument, Saudi English learners must be free from the obligation to speak and use English as monolingual native speakers. Consequently, the variety of English used by Saudi EFL learners should be acknowledge. One of the few studies that explores the variety of English which exists in KSA in the one conducted by Mahboob \& Elyas (2014) which examined published textbook used in Secondary schools in KSA. The study revealed a number of grammatical features in the book that differ from English norms. In fact a Saudi expert -consulted on those grammatical features-, stated that the features are not random mistakes but rather 'rule governed' variations of an emerging Saudi English. This study reinforces the idea that English in KSA does not adopt a westernized worldview but rather creates its own local identity that perhaps might be called Saudi English.

\subsection{Implications on Learning and Teaching}

Kachru and Nelson (1996) state that it is crucial for professionals in English language teaching to acknowledge the enormous variety of users and uses of English today. Most learners of English in expanding circle contexts don't have any contact with inner circle speakers. Therefore, it is almost impossible for those learners to learn one of the inner circle 
varieties merely from books. In regard to KSA, Alasmari \& Khan (2014) point out that large numbers of non-native speakers of English reside and work in KSA in educational institutions, business and hospital establishments. The only mean of communication between Saudis and the non-native speakers who belong to different cultural and linguistic backgrounds is English. They assert that learners in KSA should be exposed to varieties of English other than the standardized ones to help them carry intelligible communications with non-native speakers. Jenkins (2006), also, insists on the importance of exposing learners to a range of world Englishes and ELF varieties which would increase learners' confidence in their own varieties of English.

\subsection{The Two Approaches in the Saudi EFL Classroom}

It is difficult to decide which approach is more suitable for teaching English in Saudi EFL classes because there are a number of issues that must be considered before taking such decision. Jenkins (2006) points out that extensive empirical and descriptive work is needed before adopting either World Englishes or English as a Lingua franca approach at practical levels. In fact, Mahboob \& Elyas (2014) in their conducted research emphasize on the fact that any major pedagogical decisions on the issue should not be based on this individual study and that more sufficient data on the nature of English used in Saudi EFL classes must be obtained.

One point of agreement among researchers of both World Englishes and English as a lingua franca approaches is the believe that a certain variety of English chosen by a non-native speaker should reflect the speaker's sociolinguistic reality and his or her own local identity (Jenkins, 2006). Therefore, a localized variety of English is assumed to exists in KSA and should be acknowledged. However, it is reasonable to admit that putting such view into practice in Saudi EFL classrooms is not possible yet.

On one hand, the use of ELF approach in English classes might be more problematic than world Englishes. According to Seidlhofer (2005), Obtaining linguistic description of ELF at a number of levels is not sufficient to guide any pedagogical decisions. The ELF approach is based on the idea of the individuals in the expanding circle who use English to promote their identities and therefore the use of this approach might cause either generalization or more diversity and prove difficult to be put into practice. Some strategies used among ELF speakers such as code-switching which involves the use of some of the speaker's L1 vocabulary, could cause some communication failures among interlocutors.

The world Englishes approach, on the other hand, is based on the idea of creating connections between local cultures and certain varieties of English. This approach, may be slightly more suitable to the Saudi EFL context. Some scholars are advocates of the World Englishes approach being adopted in Saudi EFL classes (see Mahboob \& Elyas, 2014 and Alasmari \& Khan, 2014). They, also, emphasis on the importance of exposing Saudi learners to varieties of English other than the standardized ones to help them carry intelligible communications with non-native speakers. Alasmari \& Khan (2014) argue that The rapid economic growth in KSA and being a growing market for Asian and European countries confirm the need for World Englishes to be introduced in KSA. However, it is obvious that the variety of English 
in Saudi Arabia belonging to the expanding circle is not comparable to outer circle varieties e.g. Indian English in which English language plays a significant role. The localized variety of English which exists in KSA has not yet reached the level of outer circle varieties of English to be acknowledged. This is clearly seen in the researchers reluctance to adopt a Saudi variety of English that reflects the sociocultural backgrounds and identities of Saudi learners.

It might appear to be significantly beneficial in the future to consider the context and the purpose of learning English to determine which approach is suitable to be followed in teaching. Whether world Englishes approach or English as a lingua franca approach is adopted, an extensive effort must be done in providing data and setting appropriate tests which could cope with the ongoing negotiation of English language in both approaches.

\section{Conclusion}

This paper has examined two approaches to English language: the world Englishes approach and English as a lingua franca approach. The two approaches address slightly different kind of learners. Also, both approaches have certain advantages as well as certain limitations. The world Englishes approach might be slightly suitable to be adopt in the future for English teaching in outer circle countries - in this case Saudi EFL students. But the ELF approach appears to be difficult to put into practice at least for the present time. However, this will not be the end of the story, negotiation of English language among the speakers of the outer and expanding circles will continue and new perspectives on English in those contexts may emerge in the future. All of the different approaches to English and the different varieties of English are clear indications of the influential status of English language in the world today.

\section{References}

Alasmari, A. M., \& Khan, S. R. (2014). World Englishes in the EFL Teaching in Saudi Arabia. Arab World English Journal, 5(1), 316-325.

Bhatt, R. (2005). Expert Discourses, Local Practices, and Hybridity: The Case of Indian Englishes. In S. Canagarajah (Eds.), Reclaiming the Local in Language Policy and Practice (pp. 25-53). New Jeresy: Lawrence Erlbawm Associates.

Deterding, D., \& Kirkpatrick, A. (2006). Emerging South-East Asian Englishes and intelligibility. World Englishes, 25(3/4), 391-409. https://doi.org/10.1111/j.1467-971X.2006.00478.x

Foley, J. A. (2007). English as a Global Language: My Two Satangs' Worth. RELC Journal, 38(1), 7-17. https://doi.org/10.1177/0033688206076155

Jenkins, J. (2002). A Sociolinguistically Based, Empirically Researched Pronunciation Syllabus for English as an International Language. Applied Linguistics, 23(1), 83-103. https://doi.org/10.1093/applin/23.1.83 


\section{Macrothink}

International Journal of English Language Education

ISSN 2325-0887

2018, Vol. 6, No. 2

Jenkins, J. (2006). Current Perspectives on Teaching World Englishes and English as a Lingua Franca. TESOL Quarterly, 40(1), 157-181. https://doi.org/10.2307/40264515

Jenkins, J. (2009). Exploring Attitudes towards English as a Lingua Franca in the East Asian Context. In K. Murata, \& J. Jenkins (Eds.), Global Englishes in Asian Contexts: Current and Future Debates (pp. 40-56). Basingstoke: Palgrave Macmillan. https://doi.org/10.1057/9780230239531_4

Kachru, B., \& Nelson, C. (1996). World Englishes. In S. McKay, \& N. Hornberger (Eds.), Sociolinguistics and language Teaching (pp. 71-102). Cambridge: Cambridge University Press.

Kirkpatrick, A. (2006) Which Model of English: Native-speaker, Nativized or Lingua Franca?. In R. Rubdi, \& M. Saraceni (Eds.), English in the world: Global rules, global roles (pp. 71-84). London: Continuum.

Kubota, R. (2001). Learning Diversity from World Englishes. The Social Studies, 92(2), 69. https://doi.org/10.1080/00377990109603980

Lin, A., Wang, W., Akamatsu, N., \& Riazi, A. M. (2002). Appropriating English, expanding identities, and re-visioning the field: from TESOL to teaching English for glocalized communication(TEGCOM). Journal of Language, Identity, and Education, 1(4), 295-316. https://doi.org/10.1207/S15327701JLIE0104_4

Mahboob, A., \& Elyas, T. (2014). English in the Kingdom of Saudi Arabia. World Englishes, 33(1), 128-142. https://doi.org/10.1111/weng.12073

Rajagopalan, K. (2004) The concept of World Englishes and its implications for ELT. ELT Journal, 58(2), 111-117. https://doi.org/10.1093/elt/58.2.111

Seidlhofer, B. (2000). Mind the gap: English as a mother tongue vs. English as a lingua franca. Vienna English Working Papers 9/1, 51-68.

Seidlhofer, B. (2005). English as a lingua franca. ELT Journal, 59(4), 339-340. https://doi.org/10.1093/elt/cci064

\section{Copyright Disclaimer}

Copyright for this article is retained by the author(s), with first publication rights granted to the journal.

This is an open-access article distributed under the terms and conditions of the Creative Commons Attribution license (http://creativecommons.org/licenses/by/3.0/). 